Review article

\title{
Epidemiology of resistance to quinolones in Salmonella
}

\author{
Flemming BAGER ${ }^{\mathrm{a}}$, Reiner HeLmuth ${ }^{\mathrm{b} *}$ \\ ${ }^{a}$ Danish Veterinary Laboratory, 27 Bülowsvej, DK-1790 Copenhagen, Denmark \\ ${ }^{\mathrm{b}}$ Bundesinstitut für gesundheitlichen Verbraucherschutz und Veterinärmedizin, \\ Diedersdorfer Weg 1, 12277 Berlin, Germany
}

(Received 22 February 2001; accepted 15 March 2001)

\begin{abstract}
Fluoroquinolones account for about $11 \%$ of antimicrobial prescriptions in human medicine worldwide and represent the drug of choice for the treatment of a wide range of human infectious diseases. They were introduced into veterinary medicine in Europe in the late 1980s and early 1990s and in the USA in 1995. Following their introduction, resistant strains of bacteria, including Salmonella, started to emerge. Resistance to quinolones depends on chromosomal mutations and the subsequent spread of resistant clones. While the selective pressure caused by the use of quinolones facilitates their epidemic transmission, the resistant mutants may spread independently of quinolone use. In view of the key role of this group of antimicrobials in human medicine and the position of Salmonella as the leading cause of food-borne infections in many countries, the public health hazard posed by quinoloneresistant zoonotic Salmonella serovars has been a subject of concern. The fluoroquinolones are on the WHO list of drugs that should be reserved for human use. Considering the mounting evidence that quinolone-resistant zoonotic Salmonella are the cause of severe, sometimes fatal, infections in humans, the use of fluoroquinolones in food animals should be discontinued or severely restricted. Such an intervention should be accompanied by prudent use measures involving all other groups of antimicrobials to reduce the need for fluoroquinolones in veterinary medicine.
\end{abstract}

quinolone resistance / epidemiology

Résumé - Épidémiologie de la résistance aux quinolones chez Salmonella. Les fluoroquinolones représentent environ $11 \%$ de la totalité des prescriptions d'antibiotiques en médecine humaine et sont les antibiotiques de choix pour le traitement d'une grande variété de maladies infectieuses humaines. En médecine vétérinaire, ils ont été introduits en Europe à la fin des années 80-début des années 90, et aux USA en 1995. Après leur introduction, des souches de bactéries résistantes, dont des Salmonella, ont commencé à émerger. La résistance aux quinolones est due à des mutations chromosomiques et à la propagation ultérieure de clones résistants. Alors que la pression de sélection par utilisation de quinolones facilite leur transmission épidémique, les mutants résistants peuvent se propager indépendamment de l'utilisation de quinolones. Étant donné le rôle-clé de ce groupe d'antibiotiques en médecine humaine, et le fait que Salmonella soit la cause principale des infections alimentaires dans de nombreux pays, le problème est posé du risque pour la santé publique dû à des sérovars de

* Correspondence and reprints

Tel.: (49) 308412 2233; fax: (49) 308412 2953; e-mail: r.helmuth@bgvv.de 
Salmonella zoonotiques résistants aux quinolones. Les fluoroquinolones sont sur la liste de l'OMS des antibiotiques qui devraient être réservés à la médecine humaine. Considérant qu'il est de plus en plus évident que les Salmonella zoonotiques résistantes aux quinolones sont la cause d'infections sévères, quelquefois fatales chez l'homme, l'utilisation de fluoroquinolones chez les animaux entrant dans la chaîne alimentaire devrait être interrompue ou sévèrement restreinte. Une telle intervention devrait être accompagnée de mesures pour une utilisation prudente de tous les autres antibiotiques afin de réduire la nécessité d'utiliser des fluoroquinolones en médecine vétérinaire.

résistance aux quinolones / épidémiologie

Table of contents

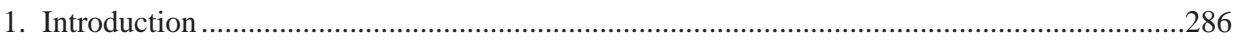

2. General considerations about epidemiology of resistance .....................................................28

3. Association between fluoroquinolone consumption and resistance ...........................................28

4. Public health aspects of fluoroquinolone use in animals.....................................................28

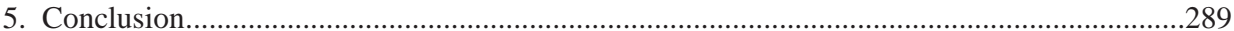

\section{INTRODUCTION}

In many countries, zoonotic Salmonella infections are still the leading cause of foodborne human infections. Based on figures given by the European Union member states, almost 200000 cases were reported in Europe in 1998 although this number might be underestimated and could be 10 -fold higher [15]. In the United States known food-borne pathogens account for an estimated 14 million illnesses, 60000 hospitalisations, and 1800 deaths [19].

Salmonellosis can lead to two types of diseases, namely typhoid fever and gastroenteritis. Typhoid fever is a generalised infection with severe symptoms and frequently occurring serious sequelae which, if untreated, are fatal in about $10 \%$ of cases. Gastroenteritis in turn is a localised infection of the gut leading to diarrhoea, fever, nausea and headaches. Salmonella Typhi and Paratyphi, strict human pathogens, cause typhoid fever. Gastroenteritis can be provoked by all the other zoonotic Salmonella (about 2400 serovars) which can occasionally cause generalised infections as well [28].
If a generalised infection and a life-threatening situation occurs, antimicrobial therapy is indicated. Today, fluoroquinolones are the agents of choice for the treatment of severe gastrointestinal infections because they have a very high level of clinical efficacy against most enteric pathogens including Salmonella [23]. Among their indications for use are cases of invasive infections caused by zoonotic Salmonella serotypes [13] and by Salmonella Typhi and Paratyphi [11].

Fluoroquinolones represent the third generation of quinolone development. The first generation of this group of compounds is represented by agents such as nalidixic acid and pipemidic acid and are characterised by limited activity against Gram-negative bacteria. The introduction in the 1980s of the fluorinated 4-quinolones offered clinicians orally and parenterally administrable agents with a broad spectrum of activity and high efficacy in a wide range of infections [2]. Their use now accounts for about $11 \%$ of overall prescriptions of antimicrobials in human medicine [27] and one of them, ciprofloxacin, is the most used antibiotic in the world [2]. 
In 1987 and 1989, the fluorinated quinolones were introduced for use in veterinary medicine in The Netherlands and Germany, respectively [18], then in 1991 in France, in 1993 in the UK [25] and they are now licensed for use in all EU countries. In the USA, sarafloxacin was licensed for veterinary use in poultry in 1995 [3] and so was enrofloxacin in 1996. The indications for the veterinary use of fluoroquinolones include a variety of intestinal and systemic infections in food animals as well as in companion animals.

\section{GENERAL CONSIDERATIONS ABOUT EPIDEMIOLOGY OF RESISTANCE}

Resistance to fluoroquinolones depends on chromosomal mutations and resistance has not yet been found to be transmitted through the dissemination of resistance genes [7]. In fact, the epidemiology of quinolone resistance in Salmonella is described exclusively by epidemic dissemination of resistant mutants, often by clonal spread. Nevertheless, the dynamics of antimicrobial resistance are multifactorial and complex. This observation applies to hospital settings $[22,24]$ and even more so to resistance among community-acquired non-typhoid Salmonella infections that represent the result of an interaction between the animal reservoir and humans.

\section{ASSOCIATION BETWEEN FLUOROQUINOLONE CONSUMPTION AND RESISTANCE}

It has long been accepted that the use of antimicrobials predisposes for the emergence and spread of resistant bacteria, e.g. [16]. However, while the use of fluoroquinolones in human medicine has been recognised as a very strong risk factor for the selection of resistant strains [22], epi- demiological studies of this association in animals do not appear to have been published. There are, however, a number of reports describing a temporal association, for example by Aarestrup et al. [1], HeurtinLe Corre et al. [14] and Malorny et al. [18].

Fluoroquinolone-resistant mutants will be selected only if the concentration of the antibiotic is less than 8-fold the MIC [2], and underdosing appears to predispose for the selection of resistant strains [6, 22]. Giraud et al. [10] confirmed this in a study where they found that one single administration of a low dose of enrofloxacin was sufficient to select resistant isolates under in vivo experimental conditions in monocontaminated gnotoxenic chickens.

The fluoroquinolones approved for use in production animals, for example sarafloxacin and enrofloxacin, are often used for group treatment in animals that are sick or only at risk of becoming sick. The drugs are most often given orally in feed or water. As the intake of feed and water varies between the individual animals, in particular in groups where some of them are sick, underdosing is difficult to avoid. Therefore, group medication of animals with fluoroquinolones increases selective pressure and predisposes for the selection of resistant strains. This problem is exacerbated, because in food animals, for example pigs and poultry, Salmonella infections are often sub-clinical. Therefore, even when fluoroquinolones are not used to treat cases of clinical salmonellosis, treatment of other infections may inadvertently place a selective pressure on Salmonella bacteria present in the herd or flock and therefore result in resistant strains.

Björkman et al. [4] studied the virulence of nalidixic acid resistant Salmonella Typhimurium and found that while resistant mutants had initially decreased virulence, the strains rapidly accumulated compensatory mutations that restored virulence without a concomitant loss of resistance. This means that quinolones may facilitate, but are not essential for, the spread of such 
resistant Salmonella strains [2]. An additional observation was reported by Malorny et al. [18] who found an increase in the incidence of quinolone-resistant Salmonella Typhimurium DT204C in a German province, before the marketing of fluoroquinolones for veterinary use in Germany. The proportion of quinolone-resistant Salmonella of bovine origin reached $49.5 \%$, before a decline in the number of isolations of the resistant clone was observed. Unfortunately these observations could not be correlated with the amounts of fluoroquinolones used. Mølbak et al. [20] were able to trace the source of an outbreak of quinolone-resistant Salmonella Typhimurium DT104 to two pig farms but failed to find evidence of quinolone use on the farms.

In their in vivo experiments, Giraud et al. [10] found that fluoroquinolone-resistant Salmonella Typhimurium could still be isolated from monocontaminated gnotoxenic birds 10 days after in vivo selection although at a drastically reduced frequency and with drastically altered growth on solid media.

In 1999, Davies et al. reported on nalidixic acid resistance in Salmonella isolated from turkeys and other livestock in Great Britain [9]. They observed an increase in nalidixic acid resistance of up to $31 \%$, especially in turkey. Resistance was especially prevalent in Salmonella Typhimurium DT104, where $78 \%$ of turkey isolates were quinolone-resistant.

\section{PUBLIC HEALTH ASPECTS OF FLUOROQUINOLONE USE IN ANIMALS}

In general, the role of the animal reservoir for antimicrobial resistance in human disease remains controversial. This also applies to fluoroquinolone-resistant Salmonella [5]. This is in marked contrast to the general recognition that food is the primary source of zoonotic Salmonella infections in humans. One explanation for the contro- versy surrounding antimicrobial resistance is that clear evidence unequivocally showing that antibiotic-resistant bacteria from animals cause human infections which are difficult to treat, is scarce. Furthermore, not all resistance phenotypes may be equally critical. For example, an antimicrobial to which an organism is resistant may not be the drug of choice for the treatment of infections in man [21]. However, this is not the case for fluoroquinolones. An additional factor contributing to the controversy may be that studies endeavouring to determine the association between the consumption of fluoroquinolones and the occurrence of resistance to this group of compounds often fail to take into account the pattern of resistance to other antimicrobials, and the possibility of co-selection by other agents, as noted by Richard et al. [22]. The transmission dynamics of resistant bacteria - even in the absence of horizontal spread of resistance genes is therefore highly complex.

Information on the public health impact of the veterinary use of fluoroquinolones may be gained by comparing the situations in the USA and UK in the early or mid1990s. Herikstad et al. [13] reported that in a nation-wide sample of 4008 isolates of non-typhoid Salmonellae from humans in the United States between 1994 and 1995 only one isolate was resistant to fluoroquinolones, and 21 to nalidixic acid. The single fluoroquinolone-resistant isolate recovered was from an infection that was most likely acquired abroad. This result occurred against a background of common fluoroquinolone use in human medicine since the mid-1980s, where their use in one teaching hospital amounted to $6.8 \%$ of the total quantity of antibacterials used [24], but where fluoroquinolones were not yet approved for use in food animals [3]. In sharp contrast to this, Threlfall et al. [25, 26] found that in the UK, where fluoroquinolones were approved for veterinary use in 1993, the proportion of fluoroquinolone-resistant Salmonella Typhimurium in humans increased 12-fold from 
about one percent in 1994 to 12 percent in 1996. Direct comparison of the proportions of fluoroquinolone-resistant isolates between the USA and the UK is difficult, because different breakpoints are used. However, the lower breakpoint used for fluoroquinolones in the UK corresponds well to the breakpoint for nalidixic acid. It is therefore clear that nalidixic acid resistance occurs much more frequently in the UK than in the USA. This appears to show that for community-acquired infections with zoonotic Salmonella serotypes, the medical use of fluoroquinolones has little impact on the occurrence of resistant strains, whereas the veterinary use of these drugs plays a major role.

It is generally accepted that Salmonella serotypes other than $S$. Typhi and $S$. Paratyphi are zoonotic and transmitted from animals to man and it is also clear that fluoroquinolone-resistant bacteria may be transmitted epidemically, without the selective interference of fluoroquinolone use [22, 27]. As early as 1994, Lontie et al. [17] suggested that the occurrence of highly fluoroquinolone-resistant Salmonella Typhimurium in three patients who had not received fluoroquinolones might be explained by its transmission from the animal reservoir. Using a number of phenotypic and genotypic characterisation criteria, Heisig et al. [12] failed to differentiate between isolates with high-level resistance to fluoroquinolones from cattle and humans. More recently, Mølbak et al. [20] demonstrated that quinolone-resistant Salmonella Typhimurium DT104 responsible for a foodborne outbreak resulting in two fatal cases could be traced back to two pig farms.

\section{CONCLUSION}

Fluoroquinolones are valuable antibiotics for the treatment of a variety of infections in human and veterinary medicine. Their use in food animals has led to increasing resistance and reduced susceptibility among zoonotic
Salmonella serotypes isolated from human patients and while the public health impact of this resistance remains a subject of controversy, there is some evidence that quinolone resistance in Salmonella Typhimurium DT104 has led to fatal infections.

Fluoroquinolones are on the WHO list of antimicrobials that should be reserved for human use [8]. Considering the public health risk posed by quinolone-resistant Salmonella and the evidence that resistant strains may disappear only slowly or not at all if the selective pressure is removed, the use of fluoroquinolones in food animals should be discontinued or severely restricted, to prevent a further increase in the occurrence of resistant strains.

However, it is important to realise that measures to prevent quinolone resistance arising in bacteria from food animals must be instituted along with the prudent use of all antimicrobials, in order to reduce other types of antimicrobial resistance that would make the use of fluoroquinolones necessary.

\section{REFERENCES}

[1] Aarestrup F.M., Jensen N.E., Jorsal S.-E., Nielsen T.K., Increased occurrence of resistance to fluoroquinolones among pathogenic bacteria in Denmark in relation to their increased use (in Danish), Dan Veterinaertidsskr. 81 (1998) 794-796.

[2] Acar J.F., Goldstein F.W., Trends in bacterial resistance to fluoroquinolones, Clin. Infect. Dis. 24. Suppl. 1 (1997) S67-S73.

[3] Anonymous, Establishment of a national surveillance programme for antimicrobial resistance in Salmonella, MMWR (Morb. Mortal. Wkly Rep.) 45 (1996) 110-111.

[4] Björkman J., Hughes D., Andersson D.I., Virulence of antibiotic-resistant Salmonella Typhimurium, Proc. Natl. Acad. Sci. USA 95 (1998) 3949-3953.

[5] Carnevale R., Molbak K., Bager F., Aarestrup F.M., Fluoroquinolone resistance in Salmonella: A web discussion, Clin. Infect. Dis. 31 (2000) 128-130.

[6] Clerch B., Bravo J.M., Llagostera M., Analysis of ciprofloxacin-induced mutations in Salmonella Typhimurium, Environ. Mol. Mutagen. 27 (1996) 110-115. 
[7] Cloeckaert A., Chaslus Dancla E., Mechanisms of quinolone resistance in Salmonella, Vet. Res. 32 (2001) 291-300

[8] Couper M.R. Strategies for the rational use of antimicrobials, Clin. Infect. Dis. Suppl. 1 (1997) S154-S156.

[9] Davies R.H.A., Teale C.J., Wray C., McLaren I.H., Jones Y.E., Chappell S., Kidd S., Nalidixic acid resistance in Salmonellae isolated from turkeys and other livestock in Great Britain, Vet. Rec. 144 (1999) 320-322.

[10] Giraud E., Brisabois A., Martel J.-L., ChaslusDancla E., Comparative studies of mutations in animal isolates and experimental in vitro and in vivo selected mutants of highly fluoroquinolone-resistant strains in the field, Antimicrob. Agents Chemother. 43 (1999) 2131-2137.

[11] Graninger W., Zedwitz-Liebenstein K., Laferl H., Burgmann H., Quinolones in gastrointestinal infections, Chemotherapy 42 Suppl. 1 (1996) 4353.

[12] Heisig P., Kratz B., Halle E., Gräser Y., Altwegg M., Rabsch W., Faber J.-P., Identification of DNA gyrase A mutations in ciprofloxacin-resistant isolates of Salmonella Typhimurium from men and cattle in Germany. Microb. Drug Resist. 1 (1995) 211-218.

[13] Herikstad H., Hayes P., Mokhtar M., Fracaro M.L., Threlfall E.J., Angulo F.J., Emerging quinolone-resistant Salmonella in the United States, Emerg. Infect. Dis. 3 (1997) 371-372.

[14] Heurtin-Le Corre C., Donnio P.Y., Bonnier M., Travert M.F., Lacourt A., Avril J.L., Incidence croissante de la résistance à l'acide nalidixique et sensibilité aux quinolones de souches de Salmonella Typhimurium isolées chez l'homme ou l'animal, Pathol. Biol. 46 (1998) 587-590

[15] Kaesbohrer A., Trends and sources of zoonotic agents in animals, feedstuffs, food and man in the European Union, Document No. SANCO/409/2000 Rev.2 of the European Commission.

[16] Levy S.B., Burke J.P., Wallace C.K., Antibiotic use and antibiotic resistance worldwide, Rev. Infect. Dis. 9 Suppl. 3 (1987) S231-S316.

[17] Lontie M., Verhaegen J., Chasseur-Libotte M.L., Verbist L., Salmonella Typhimurium highly resistant to fluoroquinolones, J. Antimicrob. Chemother. 34 (1994) 845-846.
[18] Malorny B., Schroeter A., Helmuth R., Incidence of quinolone resistance over the period 1986 to 1998 in veterinary Salmonella isolates from Germany, Antimicrob. Agents Chemother. 43 (1999) 2278-2282.

[19] Mead P.S., Slutsker L., Dietz V., McCaig L.F., Bresee J.S., Shapiro C., Griffin P.M., Tauxe R.V., Food-related Illness and Death in the United States, Emerg. Infect. Dis. 5 (1999) 607-625.

[20] Mølbak K., Baggesen D.L., Aarestrup F.M., Ebbesen J.M., Engberg J., Frydendahl K., GernerSmidt P., Petersen, A.M., Wegener H.C., An outbreak of multidrug-resistant, quinolone-resistant Salmonella enterica serotype Typhimurium DT104, N. Engl. J. Med. 341 (1999) 1420-1425.

[21] Piddock L.J.V., Does the use of antimicrobial agents in veterinary medicine and animal husbandry select antibiotic-resistant bacteria that infect man and compromise antimicrobial chemotherapy, J. Antimicrob. Chemother. 38 (1996) 1-3.

[22] Richard P., Delangle M.H., Merrien D., Barillé S., Reynaud A., Minozzi C., Richet H., Fluoroquinolone use and fluoroquinolone resistance: is there an association?, Clin. Infect. Dis. 19 (1994) 54-59.

[23] Sande M., Chambers H., Antimicrobial Agents, General Considerations, Section IX, Chemotherapy of Microbial Diseases, in: Hardman J., Limbird L., Molinoff P. et al. (Eds.), Goodman and Gilman's The Pharmacological Basis of Therapeutics, 9th ed., The McGraw-Hill Companies, New York, 1996, p. 1039.

[24] Segreti J., Connelly R., Effect of quinolone use on antimicrobial susceptibility patterns over a 5-year period, Drugs 49 Suppl. 2 (1995) 185-187.

[25] Threlfall E.J., Ward L.R., Skinner J.A., Rowe B., Increase in multiple antibiotic resistance in nontyphoidal Salmonellas from humans in England and Wales: A comparison of data for 1994 and 1996, Microb. Drug Resist. 3 (1997) 263-266.

[26] Threlfall E.J., Frost J.A., Rowe B., Fluoroquinolone resistance in salmonellas and campylobacters from humans, B.M.J. 318 (1999) 943.

[27] Thompson C.J. , The global epidemiology of resistance to ciprofloxacin and the changing nature of antibiotic resistance: a 10 year perspective, $\mathrm{J}$. Antimicrob. Chemother. 43 Suppl. A (1999) 3140.

[28] Wray C., Wray A., Salmonella in domestic animals, CABI publishing, Guilford, UK, 2000. 